\title{
Effect of diet supplementation with Ascophyllum nodosum on cow milk composition and microbiota
}

\author{
Clemencia Chaves Lopez, ${ }^{1}$ Annalisa Serio, Chiara Rossi, Giovanni Mazzarrino, Sonia Marchetti, \\ Federica Castellani, Lisa Grotta, Francesco Paolo Fiorentino, Antonello Paparella, and Giuseppe Martino \\ Faculty of Bioscience and Technology for Food, Agriculture and Environment, University of Teramo, Mosciano S. Angelo (TE), Italy 64023
}

\begin{abstract}
Iodine deficiency remains a major public health concern in many countries, including some European regions. This study aimed at understanding the effect of a supplement of marine alga Ascophyllum nodosum as a iodine fortifier in the cow diet, on the compositional and microbiological quality of milk. The results obtained in this work indicated that the dietary inclusion of $A$. nodosum exerted significant effects on cow milk composition. In particular, it increased iodine content and reduced the quantity of free amino acids without modifying the free fatty acid content. From a microbiological point of view, statistically significant differences were found in presumptive mesophilic lactobacilli, mesophilic lactococci, and Pseudomonas spp. counts. Based on a culture-independent method, milk obtained after dietary inclusion of $A$. nodosum harbored the highest number of Firmicutes (e.g., Lactococcus lactis) and the lowest number of Proteobacteria (e.g., Pseudomonas). In addition to changes in bacterial population, diet supplementation with $A$. nodosum changed the catabolic profiles of the milk community, according to Biolog Ecoplate (Biolog Inc., Hayward, $\mathrm{CA}$ ) results. The results of this study suggest that the dietary inclusion of the marine alga $A$. nodosum led to an improvement of the iodine content in milk, and to a modification of its microbiota with a positive effect on milk hygiene and transformation.
\end{abstract}

Key words: Ascophyllum nodosum, iodide supplementation, milk microbiota, Pseudomonas spp.

\section{INTRODUCTION}

Iodine is a constituent of the thyroid hormones triiodothyronine and thyroxine, as well as of the precursor

Received December 30, 2015.

Accepted April 22, 2016.

${ }^{1}$ Corresponding author: cchaveslopez@unite.it iodothyrosine. Both hormones have multiple functions as regulators of cell activity (energy metabolism) and growth, transmitters of nervous stimuli, and as important factors for brain development (Eastmann and Zimmermann, 2009). Iodine deficiency can affect all stages of human life, although iodine can be obtained by consumption of food products and enriched foods. Considering that the dietary iodine intake can vary from day to day depending on diet, a beneficial effect of increased iodine intake is primarily associated with individuals having a low intake, who can be at risk of iodine deficiency (EFSA, 2005). In fact, iodine deficiency disorders are seen at all stages of development and are particularly of concern in pregnancy and infancy because of the risk of developmental brain damage (WHO/UNICEF/ICCIDD, 2007).

Iodine deficiency remains a major public health concern in many countries, including some European countries (EFSA, 2014). In Italy, mild iodine deficiency is rather common in many areas, despite the recent efforts to increase iodine intake, and therefore goiter and other iodine deficiency disorders are still observed (Olivieri and Vitti, 2014). As a preventive measure, salt iodization has been widely used; however, considering that the use of iodized salt is voluntary, additional measures for iodine deficiency prophylaxis are necessary (Baňoch et al., 2012). The iodine of milk and milk products represents the second-most important food source of the trace element in the European Union or in the United States (Bader et al., 2005), and its concentration in cow milk ranges between 30 and 300 $\mu \mathrm{g} / \mathrm{L}$ (Moschini et al., 2010). Considerable interest has been displayed in the last years in supplementing the diet of lactating animals with iodide, by using fortified feeds either from inorganic (sodium iodide, potassium iodide, calcium iodate hexahydrate, and anhydrous calcium iodate) and organic sources (Moschini et al., 2010; Norouzian, 2011). In this respect, marine algal supplements are promising tools for iodine fortification, as they are relatively easy to incorporate into rations, contain protein and are consumer-friendly, considering regulatory limitations and concerns over the use of fish 
products in ruminant diets (Reynolds et al., 2006). Moreover, marine algae are an alternative to fish oil. In particular, microalgae are rich in eicosapentaenoic acid and docosahexaenoic acid (Spolaore et al., 2006), whereas macroalgae such as $A$. nodosum contains high quantities of the important n-3 PUFA eicosapentaenoic acid (C20:5; van Ginneken et al., 2011) and this can add nutritional value to cow milk.

Because the brown macroalga Ascophyllum nodosum contains many nutritional components such as polysaccharides, fatty acids, polyphenols, peptides (Phaneuf et al., 1999) and the iodine content varied from 482 $\mu \mathrm{g} / \mathrm{g}$ (Phaneuf et al., 1999) to $712 \mu \mathrm{g} / \mathrm{g}$ (Combet et al., 2014), meals or extracts of this alga have been examined as natural feed supplements to improve animal health and performance in the following species: lambs (Archer et al., 2007) and cattle (Kannan et al., 2007; Karatzia et al., 2012), young pigs (Turner et al., 2002), and grower-finisher pigs (Gardiner et al., 2008). Moreover, this alga has been reported to cause a short-term decrease of core body temperature ( $\mathrm{T}$ core) in cows (Archer et al., 2007) and to improve immune function during heat stress, without affecting performance (Archer et al., 2007; Karatzia et al., 2012).

As reported by some researchers (Saker et al., 2001), A. nodosum modulates the immune system of the cows; therefore, it has been hypothesized that it could affect the healthy state of the udder and consequently the microbiological composition of the milk. Nevertheless, the composition of milk microbiota could be influenced by a combination of both iodine antimicrobial properties and a healthy immune system. Thus, the aim of this study was to determine the efficacy of a supplement of marine alga $A$. nodosum as an iodine source in the cow diet, in improving the iodine content and the microbiological quality of milk. Moreover, the chemical composition of milk was also investigated to evaluate the possible effect of $A$. nodosum fortification on peculiar components such as fatty acids and free AA.

\section{MATERIALS AND METHODS}

The study was conducted using 22 multiparous dairy cows (Holstein Friesian), over a 8.5-wk period. The study consisted in 2 trials, the first from April to July 2013 and the second from April to July 2014. The experiment was carried out in Loreto Aprutino (Pescara), in Central Italy.

The cows were tied in individual stalls on a concrete floor with rubber mats and wood shavings for bedding and provided with free access to water, according to the guidelines set out by the Italian Legislation Decree 26/2014, implementing Directive 2010/63/EU with respect to animal experimentation and the care of animals used for scientific purpose.

\section{Experimental Design}

The sample of 22 cows was divided in 2 groups (control and experimental) of 11 animals, with the same age, number of calving, and lactation period. The selection of animals for the 2 groups was completely randomized and the groups were not statistically different for the following parameters: BW $(655 \pm 14.01 \mathrm{~kg})$, milk production $(42.92 \pm 0.14 \mathrm{~kg})$, and duration of lactation (DIM: $302.45 \pm 0.51 \mathrm{~d}$ ) of the year before the beginning of the trial. The experiment was repeated twice.

\section{Diet}

The diet of both groups had a TMR with the following formulation on a DM basis: corn silage $58 \%$, sainfoin hay $13 \%$, second cut alfalfa hay $6 \%$, and concentrate $23 \%$. Control concentrate (CC) and experimental concentrate (EC) were formulated using the same feed materials but the EC contained Ascophyllum nodosum (supplied by Tasco by Acadian Seaplants, Dartmouth, NS, Canada).

During a 21-d pretrial period, all cows received, in addition to the TMR, $1 \mathrm{~kg} / \mathrm{d}$ of the CC containing 1.2 $\mathrm{mg}$ of iodine (as potassium iodide) needed to satisfy their requirements. Beginning on d 22 until d 60, 19.6 $\mathrm{kg}$ of DM/d of TMR was offered to each animal of both groups. Additionally, the experimental group received 1 $\mathrm{kg} / \mathrm{d}$ of the EC contains $65 \mathrm{mg}$ of iodine through the $A$. nodosum addition, whereas the control group received 1 $\mathrm{kg} / \mathrm{d}$ of the CC. In Table 1, formulations of TMR and the 2 concentrates were reported.

Chemical analysis of TMR, CC, and EC and fatty acid composition of TMR, CC, and EC was reported in Tables 2 and 3, respectively.

Table 1. Composition of the TMR used in this experimentation

\begin{tabular}{lcc}
\hline Item & TMR $(\mathrm{g} / \mathrm{kg})$ \\
\hline Corn silage & \multicolumn{2}{c}{580} \\
Sainfoin hay & \multicolumn{2}{c}{60} \\
Alfalfa hay & \multicolumn{2}{c}{230} \\
Concentrate & \multicolumn{2}{c}{ Concentrate $(\mathrm{g} / \mathrm{kg})$} \\
& Control & Experimental $(\mathrm{g} / \mathrm{kg})$ \\
Corn meal & 630 & 530 \\
Sunflower meal & 170 & 170 \\
Soybean meal & 90 & 90 \\
Field bean meal & 80 & 80 \\
Ascophyllum nodosum & 100 \\
Vitamin and minerals & - & 30 \\
\hline
\end{tabular}

${ }^{1}$ Supplied by Tasco by Acadian Seaplants (Dartmouth, NS, Canada). 
Table 2. Chemical analysis of the feedstuff used in this study ${ }^{1}$

\begin{tabular}{lrcc}
\hline & TMR & Control concentrate & $\begin{array}{c}\text { Experimental } \\
\text { concentrate }\end{array}$ \\
\hline Item & 56.78 & 89.51 & 90.43 \\
CP (\%) & 11.17 & 16.21 & 15.77 \\
Crude fiber (\%) & 21.19 & 7.02 & 7.37 \\
Ether extract (\%) & 1.27 & 2.76 & 2.66 \\
Starch (\%) & 23.13 & 43.96 & 37.58 \\
Ash (\%) & 6.24 & 5.32 & 7.49 \\
NDF (\%) & 45.09 & 15.75 & 14.96 \\
ADF (\%) & 28.36 & 8.04 & 2.74 \\
ADL (\%) & 5.71 & 2.71 & 65.15 \\
Iodide (mg/kg) & 0.96 & 1.2 & 16.60 \\
Fatty acid (\%) & & & 0.41 \\
Palmitic acid (C16:0) & 20.46 & 21.38 & 3.58 \\
Palmitoleic acid (C16:1) & 0.41 & 0.89 & 27.05 \\
Stearic acid (C18:0) & 2.26 & 5.35 & 0.74 \\
Oleic acid (C18:1 cis-9) & 18.42 & 28.30 & 45.61 \\
Vaccenic acid (C18:1 cis-11) & 0.57 & 1.26 & 2.61 \\
Linoleic acid (C18:2) & 54.40 & 39.87 & 0.26 \\
Linolenic acid (C18:3) & 1.35 & 2.08 & 1.19 \\
Paullinic acid (C20:1) & 0.33 & - & \\
Arachidonic acid (C20:4) & 0.14 & & \\
\hline
\end{tabular}

${ }^{1}$ Mean of 2 samples.

\section{Sampling}

Feedstuff samples were taken at the beginning of the trial, while 3 milk samples (pooled from animals of each group) were collected at the end of the each 60 d trial (when iodine level was stable), whereby morning and evening milk was mixed to obtain the yields and analyzed. Udders were washed with running water, and then dried with paper towels before milking. Milk samples, collected in sterile plastic boxes, were immediately mixed with RNAlater (Sigma-Aldrich; ca. $5 \mathrm{~g}$, $1: 2 \mathrm{wt} / \mathrm{vol}$ ). Milk samples in RNAlater were stored at $-80^{\circ} \mathrm{C}$ for further RNA analyses.

\section{Chemical Analysis}

Chemical analysis of TMR and concentrates were performed according to AOAC methods: DM (AOAC

Table 3. Physical and chemical profile (mean \pm pooled SE) of control milk and milk from cows fed with Ascophyllum nodosum supplementation $(\mathrm{FSA})^{1}$

\begin{tabular}{lcccc}
\hline Item & Control milk & FSA milk & SE pooled & $P$-value \\
\hline Iodine (mg/L) & 0.92 & 1.96 & 0.26 & 0.001 \\
Fat (\%) & 3.69 & 3.51 & 0.12 & 0.528 \\
Protein (\%) & 3.47 & 3.39 & 0.27 & 0.841 \\
Lactose (\%) & 4.66 & 4.73 & 0.17 & 0.735 \\
Casein (\%) & 2.71 & 2.68 & 0.20 & 0.861 \\
Urea (\%) & 9.41 & 13.17 & 1.09 & 0.086 \\
TS (\%) & 12.35 & 12.33 & 0.46 & 1.000 \\
pH (\%) & 6.33 & 6.46 & 0.12 & 0.949 \\
SCC $\left(\times 10^{3}\right.$ cells $\left./ \mathrm{mL}\right)$ & 490 & 272 & 61.54 & 0.032 \\
\hline
\end{tabular}

International, 1995), CP (AOAC International, 2005), crude fiber (AOAC International, 2005), ether extract (Ministero Delle Politiche Agricole e Forestali, 1998), and ash (AOAC International, 2005); NDF, ADF, and ADL were determined according to the method reported by Goering and van Soest (1970). Milk composition was determined by MilkoScan FT 6000 (Foss Integrator-IMT, Foss, Padova, Italy).

Iodine analysis in all matrices was performed by inductively coupled plasma-mass spectrometry (ICPMS) Agilent 7500 quadrupole (Agilent, Palo Alto, $\mathrm{CA}$ ). Samples of $0.5 \mathrm{~g}$ of milk were homogenized with tetramethylammonium hydroxide $(0.25 M)$ and $2 \mathrm{~mL}$ of $\mathrm{H}_{2} \mathrm{O}_{2}(30 \%)$, and mineralized in a microwave (Mars 25 Express 5, CEM srl, Cologno Al Serio, Italy) at 800 $\mathrm{W}$ at a temperature of $170^{\circ} \mathrm{C}$ for $30 \mathrm{~min}$. After cooling, the samples were transferred into a sterile tube and added with distilled water to reach a volume of $15 \mathrm{~mL}$. After centrifugation $(2,500 \times g$ for $10 \mathrm{~min}$ at room temperature), samples were filtered through polytetrafluoroethylene (PTFE) syringe filters $(0.45 \mu \mathrm{m})$ and stored at $4^{\circ} \mathrm{C}$ before measurement. Distilled water was used as blank. Iodine quantification was made by using an ICP-MS. Argon was the gas used at the rate flow of 1.05 and $0.2 \mathrm{~L} / \mathrm{min}$ for transport and gas formation, respectively. The total acquisition time was $21 \mathrm{~s}$, and iodine was determined at $m / z=127$. Calibration of the instrument was carried out by using an external iodine standard with a calibration line that provided 6 calibration points equal to concentrations of $0,5,10,25$, 50 , and $100 \mathrm{mg} / \mathrm{L}$ of iodine in tetramethylammonium 
hydroxide. Before the sequence analysis, ICP-MS was auto-tuned by using the appropriate tuning solution containing $1 \mathrm{ppb}$ of different metals ( $\mathrm{Li}, \mathrm{Y}, \mathrm{Ce}, \mathrm{Tl}$, and Co).

\section{Fatty Acid Analysis}

Total mixed ration and concentrate samples were dried and ground, while milk samples were stored at $-20^{\circ} \mathrm{C}$. The lipid fraction was extracted as follows (Secchiari et al., 2003). Briefly, while $10 \mathrm{mg}$ of feed was mixed with $100 \mathrm{~mL}$ of n-hexane and shaken for 2 to $3 \mathrm{~h}, 10 \mathrm{~mL}$ of milk was mixed with $15 \mathrm{ml}$ of isopropanol and extracted with n-hexane twice. Samples were filtered and dried by Rotavapor (Steroglass, San Martino in Campo, Italy). An aliquot of $80 \mathrm{mg}$ of lipids was reconstituted in $2 \mathrm{~mL}$ of $\mathrm{n}$-hexane to proceed to transmethylation with $\mathrm{KOH}$ in methanol. The fatty acid composition was determined by gas chromatography (Focus GC, Thermo Scientific, Milan, Italy). The separation of FAME was performed with an Agilent Technology capillary column CP88 for FAME $(100 \mathrm{~m} \times$ $0.25 \mathrm{~mm}$ i.d., Agilent Technology, Milano, Italy), coated with a CB stationary phase (film thickness of $0.25 \mu \mathrm{m}$ ) connected to an FID detector. Individual FAME were identified based on the retention time of heneicosanoic acid methyl ester (C21:0), added before methylation as an internal standard. The fatty acid composition was calculated using the peak areas and was expressed on a percentage basis. The average amount of each fatty acid was used to calculate the sum of the SFA, MUFA, and PUFA.

\section{Free Amino Acid Analysis}

A total of $300 \mu \mathrm{L}$ of milk was added slowly to $2 \mathrm{~mL}$ of methanol; the solution was mixed on a vortex and centrifuged at 2,500 $\times g$ for $5 \mathrm{~min}$ at $4^{\circ} \mathrm{C}$. The supernatant was removed, and after filtration through a $0.45 \mu \mathrm{m}$ filter, analyzed for AA as previously reported (ChavesLópez et al., 2011), as follows: samples were derivatized with AccQ.Fluor reagent (6-aminoquinolyl- $N$-hydroxysuccinimidyl carbamate). Reversed phase-HPLC was performed using a Waters liquid chromatography using a Nova-Pak $\mathrm{C}_{18}$ column $(4 \mu \mathrm{m}, 3.9 \times 4.6 \mathrm{~mm})$, heated to $37^{\circ} \mathrm{C}$ in a column oven. Elution was by means of a gradient of solvent A (Waters AccQ.Tag eluent A), solvent B (acetonitrile: Aldrich Chemical Co., Milan, Italy), and solvent C (20\% methanol in Milli-Q water). The gradient was formed as follows: initial eluent $100 \%$ $\mathrm{A} ; 99 \% \mathrm{~A}$ and $1 \% \mathrm{~B}$ at $0.5 \mathrm{~min} ; 95 \% \mathrm{~A}$ and $5 \% \mathrm{~B}$ at $18 \mathrm{~min} ; 91 \% \mathrm{~A}$ and $9 \% \mathrm{~B}$ at $19 \mathrm{~min} ; 83 \% \mathrm{~A}$ and $17 \% \mathrm{~B}$ at $29.5 \mathrm{~min} ; 60 \% \mathrm{~B}$ and $40 \% \mathrm{C}$ at $33 \mathrm{~min}$ and held under these conditions for 20 min before returning to $100 \% \mathrm{~A}$. The concentration of $\mathrm{A}$ was maintained at $100 \%$ up to $65 \mathrm{~min}$, after which the gradient was changed to $60 \% \mathrm{~B}$ and $40 \% \mathrm{C}$ for a further $35 \mathrm{~min}$, before returning to the starting conditions. Individual AA were identified by comparison of their retention times with those of calibration standards. Peak areas were processed using Millennium 32 software (Waters, Milford, MA).

\section{Microbiological Analyses}

Each sample of $10 \mathrm{~mL}$ was mixed with $90 \mathrm{~mL}$ of $0.85 \%$ (wt/vol) sterile physiological saline, and homogenized in a Stomacher Lab-blender 400 Circulator (Seward, Worthing, UK) for $2 \mathrm{~min}$. Suitable serial dilutions in the same diluent were prepared. Lactic acid bacteria were enumerated on de Man, Rogosa, and Sharpe agar and enterococci on kanamycin azide agar, both incubated anaerobically by means of anaerobic jars and BBL GasPak anaerobic system envelopes (Becton Dickinson, Franklin Lakes, NJ) at $37^{\circ} \mathrm{C}$ for 48 h. Potato dextrose agar, added with chloramphenicol (Sigma-Aldrich), incubated at $25^{\circ} \mathrm{C}$ for $72 \mathrm{~h}$, was used for the enumeration of yeasts, and violet red bile glucose agar incubated at $37^{\circ} \mathrm{C}$ for $24 \mathrm{~h}$, was used for Enterobacteriaceae population. Staphylococcus aureus was enumerated in Baird Parker medium supplemented with egg yolk tellurite emulsion incubated at $35^{\circ} \mathrm{C}$ for $48 \mathrm{~h}$. Standard cultivation methods were carried out for Salmonella spp. and Listeria monocytogenes isolation as recommended by ISO 6579 (ISO, 2002) and ISO 11290-1 (ISO, 2004) procedures, respectively.

All the media were from Oxoid-Thermofisher (Rodano, Italy), except where otherwise specified.

\section{RNA Extraction from Milk Samples}

An aliquot of approximately $200 \mathrm{mg}$ of bulk milk samples of the second year, diluted in RNAlater, was used for RNA extraction by Stool total RNA purification kit (\#49400 Norgen Biotech Corporation, Thorold, Canada). This kit allows obtaining a major concentration of RNA with respect to other kits tested (data not shown). Total RNA was treated with RNase-free DNase I (Roche, Almere, the Netherlands; $10 \mathrm{U}$ of DNase for $20 \mu \mathrm{g}$ of RNA) for $20 \mathrm{~min}$ at room temperature. Quality and concentration of RNA extracts were determined by using $1 \%$ agarose- $0.5 \times$ Tris borate EDTA gels, and spectrophotometric measurements were performed at 260, 280, and $230 \mathrm{~nm}$ by using the NanoDrop ND-1000 Spectrophotometer (Thermo Scientific, Wilmington, DE). Total extracted RNA (about $2.5 \mu \mathrm{g}$ ) was tran- 
scribed to cDNA using random examers and the Tetro cDNA synthesis kit from Bioline (BIO-65043, Bioline, Taunton, MA), according to the manufacturer's instructions (Gowen and Fong, 2010).

\section{Bacterial Tag-Encoded FLX Amplicon Pyrosequencing and Data Analyses}

For each sample, $3 \mathrm{cDNA}$ samples corresponding to the 3 sampling were used for bacterial tag-encoded FLX amplicon pyrosequencing (bTEFAP); the bTEFAP analysis was performed by Research and Testing Laboratories (Lubbock, TX), according to standard laboratory procedures using a 454 FLX Sequencer (454 Life Sciences, Branford, CT). The cDNA was analyzed by bTEFAP. Primers forward 28F: GAGTTTGATCNTGGCTCAG and reverse 519R: GTNTTACNGCGGCKGCTG, based on the V1-V3 region (Escherichia coli position 27-519) of the 16S rRNA gene, were used (Suchodolski et al., 2012). The bTEFAP procedures were performed based on RTL protocols (Research and Testing Laboratories; http://www.researchandtesting. com). Raw sequence data were screened, trimmed, and filtered with default settings using the QIIME pipeline version 1.4 .0 (http://qiime.org/). Chimeras were excluded by using the $\mathrm{B} 2 \mathrm{C} 2$ (http://www.researchandtesting.com/B2C2.html; Gontcharova et al., 2010). Sequences lower than $250 \mathrm{bp}$ were removed. The FASTA sequences for each sample, without chimeras, were evaluated.

\section{Taxonomic Identification}

The sequences were first clustered into operational taxonomic unit (OTU) clusters with 100\% identity (0\% divergence) using the USEARCH sequence analysis tool (http://drive5.com/usearch). To determine the identities of bacteria, sequences were first queried using a distributed BLASTn.NET algorithm (Dowd et al., 2005) against a database of high-quality $16 \mathrm{~S}$ bacterial sequences derived from the National Center for Biotechnology Information. Database sequences were characterized as high quality based upon the criteria originally described by Ribosomal Database Project (v10.28; Cole et al., 2009). Using a .NET and C\# analysis pipeline, the resulting BLASTn outputs were compiled and validated using taxonomic distance methods, and data reduction analysis was performed as previously described (Dowd et al., 2008).

The OTU were identified using the appropriate taxonomic levels using a database of high-quality sequences derived from the National Center for Biotechnology
Information. The relative abundance of each OTU was determined for each sample, and the differences between the samples were calculated using Student's $t$-test.

\section{Community Level Catabolic Profiles}

Biolog Eco-Microplates (Biolog Inc., Hayward, CA) were used to determine bacterial community-level catabolic profiles. Samples were diluted 10-fold in sterile sodium chloride solution and dispensed $(150 \mu \mathrm{L})$ into each of the 96 wells of the Biolog Eco-Microplates. Incubation was at $30^{\circ} \mathrm{C}$ in the dark, and color development was measured at $590 \mathrm{~nm}$ using a microplate reader (Biolog Microstation), every $24 \mathrm{~h}$ up to $120 \mathrm{~h}$.

The metabolic activity for the milk microbial community in the Biolog plates was expressed as average well color development (AWCD) and calculated as reported below:

$$
\mathrm{AWCD}=\sum_{i=1}^{n} \frac{c_{i}}{n}
$$

where $c_{i}$ is the value of optical density (OD) obtained by subtracting the OD from the control well from that of each well, and $n$ is the number of substrates present in the plate $(\mathrm{n}=95)$. If the result was negative, the OD would be deemed to be zero.

Three indices, Shannon's diversity $\left(\boldsymbol{H}^{\prime}\right)$, substrate richness $(\boldsymbol{S})$, and substrate evenness $(\boldsymbol{E})$ were determined as follows: $H^{\prime}=-\Sigma p i \ln (p i)$, where $p i$ is the ratio of the activity of a particular substrate to the sums of activities of all substrate activity at $120 \mathrm{~h} ; S=$ the number of wells with a corrected absorbance greater than 0.25 , and $E=H^{\prime} / \log (S)$.

\section{Statistical Analysis}

All values are shown as means with the standard deviation and the pooled standard errors of the means. The data on microbial population and catabolic profiles of the milk community were analyzed by ANOVA oneway. The following statistical model was used:

$$
\mathrm{Y}=\mu+\mathrm{D}+\varepsilon
$$

where $\mathrm{Y}$ is the dependent variable, $\mu$ is the overall mean, D is fixed effects of diet, and $\varepsilon$ is the random error. Differences among means were studied using the least significant difference test at a $P$-value of $<0.05$, using statistical software Statistica 7.0 (Statsoft, Tulsa, OK) for Windows. 


\section{RESULTS AND DISCUSSION}

\section{Milk Composition}

Table 3 highlights the effect of cow feed supplementation with $A$. nodosum (FSA) on iodine content, which was significantly increased $(P<0.05)$. In fact, control milk showed a iodide content of about $0.920 \mathrm{mg} / \mathrm{L}$, which is in line with that reported by Watutantrige Fernando et al. (2013) for commercial cow milk in Italy, whereas an average iodide content of $1.96 \mathrm{mg} / \mathrm{L}$ was determined in milk samples from treated cows. Considering that the daily intake of a cup of milk (corresponding to $250-300 \mathrm{~mL}$ ) provides $0.570 \mathrm{mg}$ of iodine that are under the limit of the tolerable upper intake level of the World Health Organization $(1,000 \mu \mathrm{g}$ of iodine per day), our result represents an improvement in terms of milk nutritional value.

Although the increase of iodine content in milk after feed supplementation with inorganic forms of iodine is well documented in literature (Schöne et al., 2009; Moschini et al., 2010; Norouzian, 2011), few studies (Mosulishvili et al., 2002; Antaya et al., 2015) have been carried out on the increase of iodine in cow milk after feed supplementation with algae. Brown seaweeds have the unique ability to concentrate iodine from seawater, and certain species accumulate up to 1 million fold and therefore constitute an important source of iodine (Dierick et al., 2009). The iodine content of $A$. nodosum used in this study was $680 \mathrm{mg} / \mathrm{kg}$, which is lower than the values reported by other authors (Doty et al., 1987) that ranged from 700 to $1,200 \mathrm{mg} / \mathrm{kg}$. Also, other algae species such as Laminaria digitata and $L$. japonica contain high inorganic iodine content (Wang, 1995; Hou et al., 1997). No significant differences were evidenced in fat, proteins, lactose, casein, and TS content in the milk from the 2 groups of cows (Table 3 ). These findings are in agreement with those reported by Karatzia et al. (2012), whereas other researchers (Cvetkovic et al., 2005) found that milk production and milk protein content were increased after feed supplementation with $A$. nodosum. In the present research, the most significant differences were found in SCC, which in FSA milk was half of that of control milk, suggesting that diet positively affected the health quality of milk. Nutritional effects on immune function in dairy cows have been discussed in literature (Allen et al., 2001; van Knegsel et al., 2012). Allen et al. (2001) reported that $A$. nodosum supplementation can enhance immune function and overall animal health, probably due to its antioxidant activity, whereas Turner et al. (2002) highlighted that the seaweed extract had little positive effect on immune function in pigs fed with $A$. nodosum seaweed extract. On the contrary, van Knegsel et al. (2012) did not evidence any improvement on negative energy balance and health in cows fed with the marine alga Schizochytrium spp.

\section{Free Fatty Acid Profile}

Although $A$. nodosum used in this study had a high content of oleic acid, C18:1 cis-9 (41.23\%), C18:1 cis7 (5.58), and arachidonic acid C20:4 (6.4\%; Table 2), no significant differences were observed in the total free fatty acids in milk fat between the groups during the experimental time (Table 4). Antaya et al. (2015) reported very small differences in milk fatty acid composition in response to a diet supplemented with $A$. nodosum that was likely not biologically important. It is well known that free fatty acid content and diversity in milk is influenced by dietary characteristics, and namely fatty acid intake, fatty acid metabolism in the rumen, lipid mobilization, and fatty acid metabolism in the mammary gland.

\section{Free Amino Acid Profile}

The analyses of free AA clearly showed significant differences $(P<0.05)$ between milk from treated ani-

Table 4. Effect of diet supplementation with Ascophyllum nodosum (FSA) on fatty acid profile ( $\%$ of total fatty acids) of milk

\begin{tabular}{lrrrr}
\hline Fatty acid & Control milk & FSA milk & SE pooled & $P$-value \\
\hline C4:0 & 2.76 & 2.78 & 0.30 & 0.944 \\
C6:0 & 2.16 & 2.40 & 0.21 & 0.685 \\
C8:0 & 1.47 & 1.68 & 0.13 & 0.418 \\
C10:0 & 3.39 & 3.88 & 0.24 & 0.231 \\
C11:0 & 0.39 & 0.44 & 0.03 & 0.464 \\
C12:0 & 3.92 & 4.36 & 0.24 & 0.306 \\
C14:0 & 12.03 & 12.89 & 0.51 & 0.325 \\
C15:0 & 1.13 & 1.16 & 0.04 & 0.708 \\
C16:0 & 28.11 & 29.27 & 0.64 & 0.140 \\
C17:0 & 0.64 & 0.58 & 0.01 & 0.206 \\
C18:0 & 7.63 & 6.79 & 0.35 & 0.187 \\
SFA & 63.65 & 66.26 & 1.16 & 0.481 \\
C14: 1 & 1.15 & 1.22 & 0.06 & 0.481 \\
C16:1 & 1.88 & 1.69 & 0.08 & 0.177 \\
C18:1 trans-11 & 1.20 & 1.34 & 0.31 & 0.841 \\
C18:1 cis-9 & 22.38 & 20.54 & 0.02 & 0.345 \\
MUFA & 26.62 & 24.79 & 1.03 & 0.317 \\
C18:2n-6 & 2.32 & 2.64 & 0.19 & 0.268 \\
C18:3n-3 & 0.64 & 0.67 & 0.02 & 0.522 \\
CLA cis-9,trans-11 & 0.33 & 0.32 & 0.02 & 0.905 \\
C20:4 & 0.15 & 0.19 & 0.03 & 0.181 \\
PUFA & 3.44 & 3.84 & 0.20 & 0.266 \\
Others & 6.26 & 5.09 & 0.94 & 0.240 \\
\hline
\end{tabular}

Letters in the same row indicate significant differences $(P \leq 0.05)$ between control and FSA milk, analyzed by $t$-test $(P<0.05)$.

${ }^{1}$ Results are the mean and pooled SE of 3 samples of the same pooled milk in 2 different years $(\mathrm{n}=6)$. 
Table 5. Influence of diet supplementation with Ascophyllum nodosum (FSA) on free amino acids (FAA; $\mathrm{mg} / \mathrm{L})^{1}$

\begin{tabular}{lrccc}
\hline FAA & Control & FSA milk & SE pooled & $P$-value \\
\hline Cysteic acid & 4.06 & 3.85 & 0.15 & 0.41 \\
Tau & 1.20 & 0.10 & 0.37 & 0.005 \\
Asp & 1.46 & $\mathrm{ND}^{2}$ & 0.49 & 0.000 \\
Glu & 16.60 & 8.60 & 2.76 & 0.03 \\
Gly & 5.23 & 3.47 & 0.71 & 0.11 \\
Ala & 2.54 & 1.48 & 0.39 & 0.081 \\
Cys & 1.35 & 0.99 & 0.15 & 0.203 \\
Val & 2.06 & 1.47 & 0.21 & 0.060 \\
Leu & 0.40 & $\mathrm{ND}$ & 0.14 & 0.050 \\
His & 0.69 & 0.32 & 0.16 & 0.216 \\
Trp & 2.49 & 1.25 & 0.46 & 0.091 \\
Orn & 2.54 & 1.28 & 0.44 & 0.05 \\
Lys & 7.85 & 5.40 & 0.91 & 0.10 \\
Pro & 3.64 & 3.14 & 0.24 & 0.310 \\
Total & 55.45 & 31.36 & 9.63 & 0.032 \\
\hline Lettr & &
\end{tabular}

Letters in the same row indicate significant differences $(P \leq 0.05)$ between control and FSA milk, analyzed by $t$-test $(P<0.05)$.

${ }^{1}$ Results are the mean and standard deviation of 3 samples of the same pooled milk in 2 different years $(\mathrm{n}=6)$.

${ }^{2} \mathrm{ND}=$ not detected with the method used.

mals and control. In fact, in control milk samples the total free AA were higher (ca. $56 \mathrm{mg} / \mathrm{L}$ ) than in FSA milk $(31.44 \mathrm{mg} / \mathrm{L})$. Overall, the differences were in the content of Tau, Asp, Glu, Leu, and Orn (Table 5), and particularly the 3 most abundant free AA were Glu $(16.81 \mathrm{mg} / \mathrm{L})$, Lys $(7.85 \mathrm{mg} / \mathrm{L})$, and Gly $(5.23 \mathrm{mg} / \mathrm{L})$. These considerable levels of free AA could be correlated with higher levels of proteolytic bacteria and in particular of Pseudomonas group, which was present in higher counts in the control milk. In fact, psychrotrophic Pseudomonas spp. are known for their production of metallo-proteases during the refrigerated storage of raw milk (Marchand et al., 2009). On the other hand it is has to be considered that somatic cells are a source of a large range of enzymes such as lipases, glycosidases, and proteases (peptidases and aminopeptidases), that are released into milk after their lysis (Li et al., 2014). Although higher activity of aminopeptidases could be observed in cow's milk from infected mammary glands (Larsen et al., 2004), they could be present in milk of healthy cows (Jóźwik et al., 2004). As reported in Table 3, SC were higher in control milk, thus we can hypothesize that the enzymatic system of whole milk and somatic cells could also have contributed to the major content of AA in the control milk.

\section{Microbiological Analyses}

Several parameters influenced the microbiota present in raw milk, derived from the teat canal, the skin surface, the surrounding air, feedstuffs, as well as other environmental factors including housing conditions, the quality of water supply, and equipment hygiene (Quigley et al., 2013). The cultivable microbiota of the main groups in the 2 types of milk is depicted in Table 6 . The milk pathogens Salmonella spp. and L. monocytogenes were below the detection limits of the methods chosen (absence in $25 \mathrm{~g}$ of sample). The absence of $S$. aureus (detection limit $2 \log \mathrm{cfu} / \mathrm{mL}$ ) could indicate that the sanitation procedure had efficiently removed this species (Cleto et al., 2012). With S. aureus being one of the species responsible for mastitis, its absence could also be related to a good sanitary state of the animals.

As evidenced, the counts of mesophilic aerobic bacteria, psychrotrophic bacteria, and yeasts were not different between the 2 types of milk, whereas statistically significant differences were found in presumptive mesophilic lactobacilli, mesophilic lactococci, and Pseudomonas spp. In fact, the counts of these groups were lower in FSA milk, with a reduction of about $1.2 \mathrm{log}$ $\mathrm{cfu} / \mathrm{mL}$ for presumptive Pseudomonas spp., $1.0 \mathrm{log} \mathrm{cfu} /$

Table 6. Mean values and range of cultivable cells (log $\mathrm{cfu} / \mathrm{g}$ ) of the main microbial groups in the milk obtained from control and from cows with diet supplemented with Ascophyllum nodosum (FSA) ${ }^{1}$

\begin{tabular}{lcccc}
\hline Item & Control milk & FSA milk & SE pooled & $P$-value \\
\hline Mesophilic aerobic bacteria & 4.7 & 4.7 & 0.08 & 0.009 \\
Psychrotrophic aerobic bacteria & 4.8 & 4.7 & 0.13 & 1.000 \\
Mesophilic lactobacilli & 4.5 & 3.5 & 0.26 & 0.732 \\
Mesophilic lactococci & 4.3 & 3.8 & 0.18 & 0.001 \\
Enterococci & 3.6 & 2.4 & 0.29 & 0.060 \\
Pseudomonas spp. & 4.5 & 3.3 & 0.27 & 0.003 \\
Total coliforms & 3.9 & 3.3 & -17 & 0.0006 \\
Listeria monocytogenes & $\mathrm{Abs}^{2}$ & $\mathrm{Abs}$ & - & - \\
Salmonella spp. & $\mathrm{Abs}$ & $\mathrm{Abs}$ & - \\
Staphylococcus aureus & $<2$ & $<2$ & 0.11 & 0.010 \\
Yeasts & 2.7 & 3.0 & - \\
\hline
\end{tabular}

${ }^{1}$ Results are the mean and standard deviation of 3 different samples taken at 3 different times.

${ }^{2}$ Abs. $=$ absent in the 25 -g sample analyzed. Minimum detectable limit for the assay: $2 \log \mathrm{cfu} / \mathrm{g}$. 
$\mathrm{mL}$ for presumptive mesophilic lactobacilli, and $0.5 \mathrm{log}$ $\mathrm{cfu} / \mathrm{mL}$ for presumptive mesophilic lactococci. These results could be attributed to either the antimicrobial activity of iodide or to a better sanitary state of the udder; in fact, $A$. nodosum has been reported to improve animal health (Turner et al., 2002; Archer et al., 2007; Kannan et al., 2007; Gardiner et al., 2008; Karatzia et al., 2012).

\section{Pyrosequencing Analysis of the Metabolically Active Bacteria}

Pyrosequencing of $16 \mathrm{~S}$ rRNA, a culture-independent method, was carried out using RNA as a template, and the OTU found during processing were active members of the microbial community in the milk samples. A total of 197,385 raw sequence reads of $16 \mathrm{~S}$ rRNA gene amplicons were obtained (average length, $515 \mathrm{bp}$ ). Several differences were found between the 2 milk types analyzed. In particular, whereas control cows' milk included mainly Firmicutes (50.0\%), Proteobacteria (25.0\%), and Bacteroidetes (25.0\%), in FSA milk, the phylum Firmicutes dominated (57.14\%), and Proteobacteria, Bacteroidetes, and Actinobacteria appeared at $14.28 \%$ each. In a recent study on raw cow milk, the dominance of the phyla Firmicutes $(80.51 \%$ ) and a significant proportion of Proteobacteria (9.20\%), followed by Bacteroidetes and Actinobacteria, were reported (Quigley et al., 2013). Such findings would invoke a mechanism either of improving nutrient capture from feed consumed or decreasing maintenance (e.g., immune response) requirements, or presumably reflecting a lack of competitiveness of the proteobacteria in the FSA milk. To our knowledge, no studies have been published regarding the $16 \mathrm{~S}$ rRNA pyrosequencing of milk microbiota obtained from cows fed algae.

In control milk, 5 OTU classified at the genus level were identified, with the predominance of Pseudomonas genus (73.19\%), followed by Lactococcus $(22.14 \%)$, Staphylococcus (3.90\%), and Bacteroides (0.70\%). In FSA milk, 7 OTU at genus level were identified, with Lactococcus genus being predominant (66.37\%), whereas Pseudomonas was present at $32.87 \%$, and the subdominant population belonged to phyla Firmicutes (Staphylococcus, Enterococcus, and Clostridium from 0.03 to $0.16 \%$ ), Bacteroidetes (Bacteroides 0.35\%), and Actinobacteria (Microbacterium 0.05\%).

Figure 1 shows the percent distribution of the OTU assigned at the species level in the 2 types of milk, when such assignment was possible. Whereas gram-negative bacteria affiliated to the gamma-proteobacteria class prevailed in control milk, FSA milk was dominated by gram-positive bacteria belonging to the Bacillus class.
In particular, reads within the Pseudomonadaceae family (Proteobacteria phylum) were attributed to the Pseudomonas genus, with the highest percentage for control milk $(73.19 \%)$, which was not attributed at the species level with the exception of Pseudomonas jessenii that was more abundant in control samples (1.9\%) than in FSA milk. Pseudomonas spp. are considered as the predominant psychrotolerant bacteria in raw milk at low temperature (Raats et al., 2011) and are likely to be found in the milking environment (e.g., the milking machine system), where they can first come into contact with the teat and subsequently enter into the udder through the milking process (Delbès et al. 2007). The reduction of this microbial group in FSA milk is considered positive because these microorganisms have a potential to secrete heat-stable proteolytic and lipolytic enzymes, thus playing an important role in milk spoilage after long periods of cold incubation (Raats et al., 2011).

With regard to lactic acid bacteria, included in the family Streptococcaceae (Firmicutes), and also well adapted to low temperatures (Quigley et al., 2013), this group was represented by the genus Lactococcus, of which the species Lactococcus lactis comprised $32.2 \%$ of all sequences identified in control samples and was dominant in FSA milk (64.8\% of the reads), Lactococcus raffinolactis $(2.2 \%$ in control milk and $1.6 \%$ in FSA milk), and Lactococcus garvieae that accounted for $0.1 \%$ of the reads. The increase of Lc. lactis in FSA milk is particularly valuable because this species has a technological importance for its positive effect on cheese. Moreover, many strains of Lc. lactis are bacteriocin producers, and therefore this species could play a role in the reduction of the incidence of mastitis. In fact, colonization of the teat end by nonpathogens may be capable of inhibiting the development of mastitis either by antagonism or competitive exclusion mechanisms (Gill et al., 2006). Lactococcus garvieae and Lc. raffinolactis are commonly isolated as nondominant species in the dairy environment, (e.g., in natural starter cultures, raw milk, curd, and cheese; Blaiotta et al., 2002).

The detected Staphylococcaceae sequences were present with Staphylococcus spp., which was found to be more abundant in control milk $(3.96 \%)$ than in FSA milk $(0.02 \%)$. This could be interpreted as a positive result, as Staphylococcus spp. could be associated with mastitis. Several other bacteria often associated with dairy environments were also detected but at low levels. This is the case of Enterococcus faecalis that comprised $0.16 \%$ of all sequences identified, and Clostridium spp. and Microbacterium spp., which comprised $0.1 \%$ of the total sequence reads only in FSA milk. The presence 
A
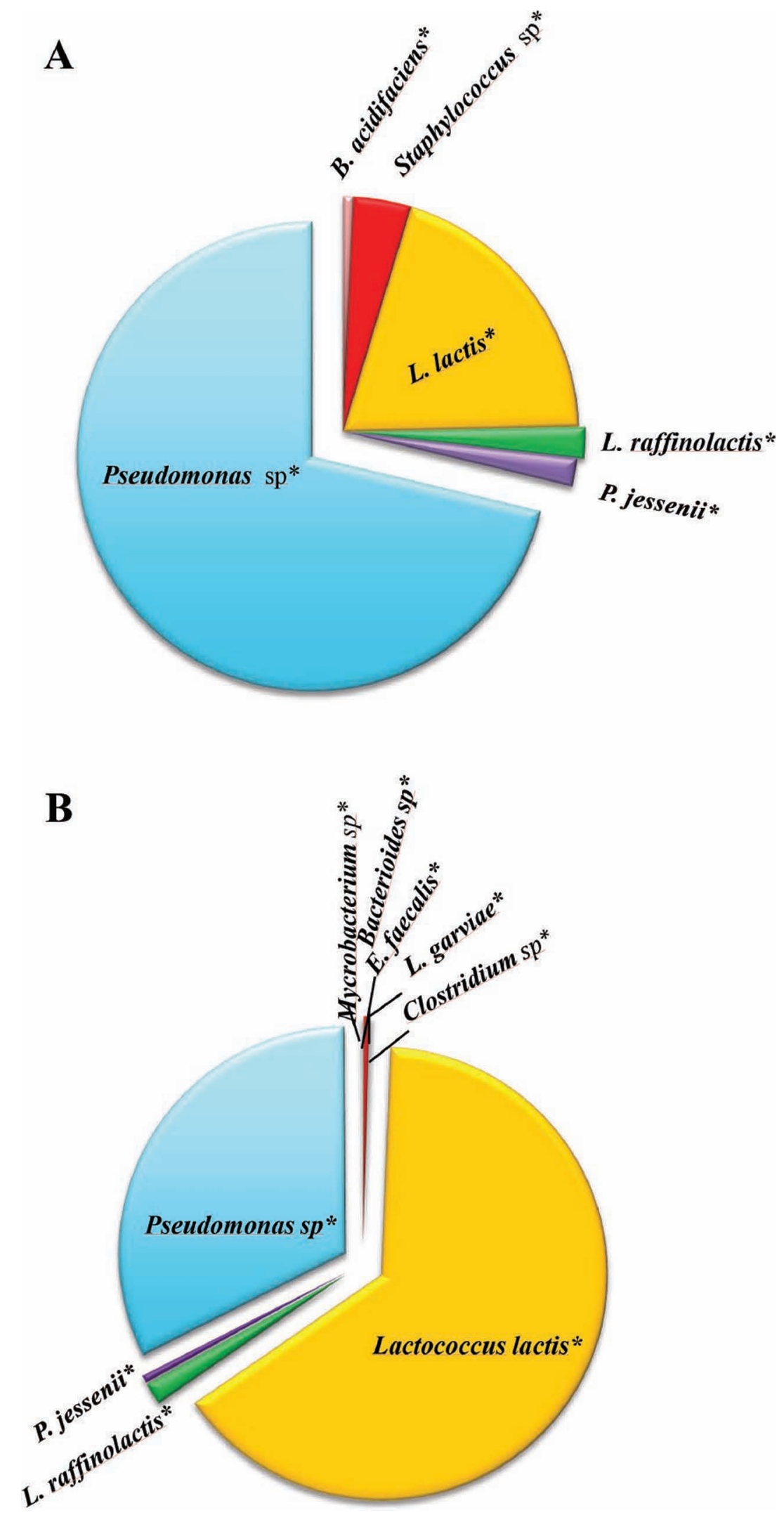

Figure 1. Percentage distribution of the operational taxonomic units (OTU) assigned at the species level in control milk (A), and in milk obtained after cow diet supplemented with Ascophyllum nodosum (FSA; B), after 16S rRNA analysis and sequencing. Color version available online. 
of obligate anaerobes belonging to Clostridiales in raw cow milk has been reported in other studies, and their occurrence has been correlated with the environment, and in particular with grass or maize silage (Raats et al., 2011), whereas enterococci are reported to be frequently isolated from Mediterranean cheeses where they exert metabolic activities that could contribute to the development of peculiar sensory properties (Serio et al., 2010).

The proportion of Bacteroides species was altered by the change in diet, with control milk showing higher abundance of Bacteroides acidifaciens (0.7\%), which has been reported as one of the predominant species responsible for promoting $\operatorname{IgA}$ production in the large intestine, important for the host, as it reduces the risk of infection and maintains a suitable intestinal environment for the appropriate commensal population (Yanagibashi et al., 2013). In FSA milk, this particular species was not detected, although Bacteroides spp. were present $(0.35 \%$ of the reads).

\section{Catabolic Profiles of the Milk Community}

In this study, in addition to changes in bacterial population, diet supplementation with $A$. nodosum changed the catabolic profiles of the milk community. It is well known that the competitiveness of populations is determined by a variety of factors, including their nutritional requirements and their generation times under the prevailing conditions, as well as antagonistic and synergistic interactions among the populations. The sole carbon source utilization patterns of microbial samples determined using the Biolog assay could be used as a functionally based measure for classifying heterotrophic microbial communities. In this study, despite varying intensity levels, a total of 31 carbon sources were positive in FSA milk already after $24 \mathrm{~h}$ of incubation. As evidenced in Figure 2, the relative utilization of carbon sources (AA, carbohydrates, carboxylic acids, amines, and polymers) varied in the 2 milk types. Differences in carbon source utilization in the Biolog microplates are related to the color response in a given well, which is related to the number of microorganisms able to use the substrate within that well. Increased color development in certain response wells suggests that the inoculum contained a larger number of microorganisms able to use the substrate. Overall, carbohydrates and carboxylic acids were the chemical classes mainly used by both types of milk community. However, in FSA milk, these compounds were more intensively degraded by microbial community, and in particular the following compounds were consumed: Dgalacturonic acid, glucose 1-phosphate, D,L- $\alpha$-glycerol

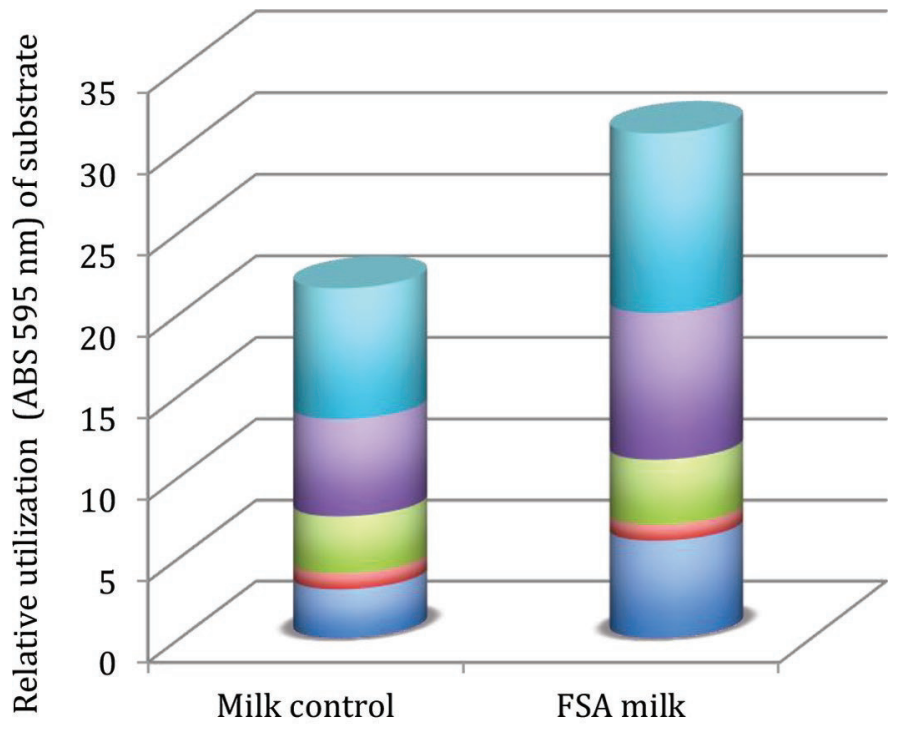

$\begin{array}{ll}\square \text { Carbohydrates } & =\text { Organic acids } \square \text { Amino acids } \\ \square \text { Amines } & =\text { Polymers }\end{array}$

Figure 2. Relative utilization (absorbance, ABS, at $595 \mathrm{~nm}$ ) of carbon sources (AA, carbohydrates, carboxylic acids, amines, and polymers) in control milk and in milk obtained after cow diet supplemented with Ascophyllum nodosum (FSA). Color version available online.

phosphate, pyruvic acid methyl ester, $\alpha$-cyclodextrine, and glycogen. Catabolic profiles were also determined by using the indices $H^{\prime}, S$, and $E$ (Table 7 ). Whereas Shannon diversity $\left(H^{\prime}\right.$ index) did not show significant differences $(P>0.05)$ in substrate utilization by the microbial communities of 2 types of milk, the $S$ index (substrate richness) was higher $(P<0.05)$ in FSA milk $(28.33 \pm 1.52$ for FSA milk). The $E$ index, a measure of the statistical significance (equitability) of the values of $H^{\prime}$ and $S$, showed values of 2.37 and 2.29 for control milk and FSA milk, respectively (Table 7). Apparently, the observed patterns of substrate oxidation were not caused by the numerically dominant populations in the community at the time of inoculation, but instead reflected the altered community composition that developed during incubation of the Biolog plates (Smalla et al., 1998).

Our results suggest that supplementation of diet with A. nodosum could contribute to the establishment of different microbial populations in the teat canal. As milk microorganisms may come from the teat surface litter in which the cows laid before milking (Zdanowicz et al., 2004), as well as from the natural microbial community of the cow's skin, further investigations would be needed to evaluate the effect of the changes observed on the microbial ecology of the teat canal. 
Table 7. Biodiversity measures of total and metabolically active microbiota of milk from control and milk from cows with diet supplemented with Ascophyllum nodosum (FSA) milk ${ }^{1}$

\begin{tabular}{lccc}
\hline Item & Shannon's diversity $\left(H^{\prime}\right)$ & Substrate richness $(S)$ & Substrate evenness $(E)$ \\
\hline Control milk & $3.11 \pm 0.25^{\mathrm{a}}$ & $21.33 \pm 2.08^{\mathrm{a}}$ & $2.37 \pm 0.12^{\mathrm{a}}$ \\
FSA milk & $3.34 \pm 0.34^{\mathrm{a}}$ & $28.33 \pm 1.52^{\mathrm{b}}$ & $2.29 \pm 0.23^{\mathrm{a}}$
\end{tabular}

a,b Letters in the same row indicate significant differences $(P \leq 0.05)$ between control and FSA milk, analyzed by LSD test $(P<0.05)$. Letters in the same column indicate significant differences $(P \leq 0.05)$ between control milk and FSA milk analyzed by LSD test $(P<0.05)$.

${ }^{1}$ Results are the mean and standard deviation of 3 different samples of the same bulk milk in 2 different years $(\mathrm{n}=6)$.

\section{CONCLUSIONS}

The results obtained in this work indicated that dietary inclusion of $A$. nodosum exerted significant effects on cow milk composition. In fact, iodine content in milk from $A$. nodosum fed cows increased below the current regulatory limit, and this represents an important health claim for the milk industry. Moreover, significant changes were observed in milk populations, with a reduction of psychrotrophic Pseudomonas that might have a positive effect on milk shelf life. In addition, the increase of Lactococcus lactis in FSA milk and the greater substrate consume are particularly valuable, suggesting a potential positive effect on the derived cheese, as this species is commonly used as a starter in milk caseification. Finally, no significant changes were observed in the lipid composition of milk, although the pattern of free AA was changed following A. nodosum feed supplementation. In conclusion, the dietary inclusion of $A$. nodosum led to an improvement of the iodide content in milk, and to modification of its microbiota, that could have a positive effect on milk hygiene and dairy processing.

\section{ACKNOWLEDGMENTS}

This work is part of the project "Innovazione della filiera bovina da latte in Abruzzo per produzioni lattiero-casearie ad elevato contenuto salutistico ed ecosostenibile," supported by a grant from Rural Development Plan 2007-2013-MISURA 1.2.4-Regione Abruzzo (Italy), project manager Giuseppe Martino. The authors are grateful to "Associazione Regionale Allevatori d'Abruzzo" (Italy) for the kind cooperation.

\section{REFERENCES}

Allen, V. G., K. R. Pond, K. K. Saker, J. P. Fontenot, C. P. Bagley, R. L. Ivy, R. R. Evans, C. P. Brown, M. F. Miller, J. L. Montgomery, T. M. Dettle, and D. B. Wester. 2001. Tasco-forage: III. Influence of a seaweed extract on performance, monocyte immune cell response and carcass characteristics in feedlot-finished steers. J. Anim. Sci. 79:1032-1040.
Antaya, N. T., K. J. Soder, J. Kraft, N. L. Whitehouse, N. E. Guindon, P. S. Erickson, A. B. Conroy, and A. F. Brito. 2015. Incremental amounts of Ascophyllum nodosum meal do not improve animal performance but do increase milk iodine output in early lactation dairy cows fed high-forage diets. J. Dairy Sci. 98:1991-2004.

AOAC International. 1995. Official Methods of Analysis. 16th ed. AOAC Int., Washington, DC.

AOAC International. 2005. Official Methods of Analysis. 18th ed. AOAC Int., Gaithersburg, MD.

Archer, G. S., T. H. Friend, D. Caldwell, K. Ameiss, and P. D. Krawczel. 2007. Effect of the seaweed Ascophyllum nodosum on lambs during forced walking and transport. J. Anim. Sci. 85:225-232.

Bader, N., U. Möller, M. Leiterer, K. Franke, and G. Jahreis. 2005. Tendency of increasing iodine content in human milk and cow's milk. Exp. Clin. Endocrinol. Diabetes 113:8-12.

Baňoch, T., M. Svoboda, J. Kuta, A. Saláková, and Z. Fajt. 2012. The effect of iodine from iodine-enriched alga Chlorella spp. on the pork iodine content and meat quality in finisher pigs. Acta Vet Brno 81:339-346.

Blaiotta, G., O. Pepe, G. Mauriello, F. Villani, R. Andolfi, and G. Moschetti. 2002. 16S-23S rDNA intergenic spacer region polymorphism of Lactococcus garvieae, Lactococcus raffinolactis and Lactococcus lactis as revealed by PCR and nucleotide sequence analysis. Syst. Appl. Microbiol. 25:520-527.

Chaves-López, C., A. Paparella, R. Tofalo, and G. Suzzi. 2011. Proteolytic activity of Saccharomyces cerevisiae strains associated with Italian dry-fermented sausages in a model system. Int. J. Food Microbiol. 150:50-58.

Cleto, S., S. Matos, L. Kluskens, and M. J. Vieira. 2012. Characterization of contaminants from a sanitized milk processing plant. PLoS ONE 7:e40189.

Cole, J. R., Q. Wang, E. Cardenas, J. Fish, B. Chai, R. J. Farris, A. S. Kulam-Syed-Mohideen, D. M. McGarrell, T. Marsh, G. M. Garrity, and J. M. Tiedje. 2009. The ribosomal database project: Improved alignments and new tools for rRNA analysis. Nucleic Acids Res. 37:D141-D145.

Combet, E., Z. F. Ma, F. Cousins, B. Thompson, and M. E. Lean. 2014. Low-level seaweed supplementation improves iodine status in iodine-insufficient women. Br. J. Nutr. 112:753-761.

Cvetkovic, B., M. J. Brouk, and J. E. Shirley. 2005. Response of heat stressed lactating dairy cattle fed dried seaweed meal. J. Dairy Sci. 88:1920. (Abstr.)

Delbès, C., L. Ali-Mandjee, and M. C. Montel. 2007. Monitoring bacterial communities in raw milk and cheese by culture-dependent and -independent 16S rRNA gene-based analyses. Appl. Environ. Microbiol. 73:1882-1891.

Dierick, N., A. Ovyn, and S. De Smet. 2009. Effect of feeding intact brown seaweed Ascophyllum nodosum on some digestive parameters and on iodide content in edible tissues in pigs. J. Sci. Food Agric. 89:584-594.

Doty, M. S., J. F. Caddy, and B. Santelices, ed. 1987. Case studies of seven commercial seaweed resources. FAO Fish Tech Pap. 311 p.

Dowd, S. E., R. D. Wolcott, Y. Sun, T. McKeehan, E. Smith, and D. Rhoads. 2008. Polymicrobial nature of chronic diabetic foot ulcer biofilm infections determined using bacterial tag encoded FLX amplicon pyrosequencing (bTEFAP). PLoS ONE 3:e3326. 
Dowd, S. E., J. Zaragoza, J. R. Rodriguez, M. J. Oliver, and P. R. Payton. 2005. Windows. NET network distributed basic local alignment search toolkit (W.ND-BLAST). BMC Bioinformatics 6:93.

Eastmann, C. J., and M. Zimmermann. 2014. The iodine deficiency disorders. Accessed Oct. 12, 2015. http://www.thyroidmanager. org.

EFSA. 2005. EFSA Scientific Panel on Additives and Products or Substances used in Animal Feed on the request from the Commission on the use of iodine in feedingstuffs. Opinion of the Scientific Panel on Additives and Products or Substances used in Animal Feed on the request from the Commission on the use of iodine in feedingstuffs. (Question N ${ }^{\circ}$ EFSA-Q-2003-058). Adopted on 25 January 2005. EFSA J. 168:1-42.

EFSA. 2014. EFSA NDA Panel (EFSA Panel on Dietetic Products Nutrition and Allergies). Scientific opinion dietary reference values for iodine. EFSA J. 12:3660.

Gardiner, G. E., A. J. Campbell, J. V. O'Doherty, E. Pierce, P. B. Lynch, F. C. Leonard, C. Stanton, R. P. Ross, and P. G. Lawlor. 2008. Effect of Ascophyllum nodosum extract on growth performance, digestibility, carcass characteristics and selected intestinal microflora populations of grower-finisher pigs. Anim. Feed Sci. Technol. 141:259-273.

Gill, J. J., P. M. Sabour, J. Gong, H. Yu, K. E. Leslie, and M. W Griffiths. 2006. Characterization of bacterial populations recovered from the teat canals of lactating dairy and beef cattle by $16 \mathrm{~S}$ rRNA gene sequence analysis. FEMS Microbiol. Ecol. 56:471-481.

Goering, H. K., and P. J. van Soest. 1970. Forage analyses. Agriculture Handbook 379. Agric. Res. Serv. USDA, Washington, DC.

Gontcharova, V., E. Youn, R. D. Wolcott, E. B. Hollister, T. J. Gentry, and S. E. Dowd. 2010. Black box chimera check (B2C2): A Windows-based software for batch depletion of chimeras from bacterial 16S rRNA gene datasets. Open Microbiol. J. 4:47-52.

Gowen, C. M., and S. S. Fong. 2010. Genome-scale metabolic model integrated with RNAseq data to identify metabolic states of Clostridium thermocellum. Biotechnol. J. 5:759-767.

Hou, X. L., C. F. Chai, Q. F. Qian, X. J. Yan, and X. Fan. 1997. Determination of chemical species of iodine in some seaweeds (I). Sci. Total Environ. 204:215-221.

ISO. 2002. ISO 6579:2002. Microbiology of food and animal feeding stuffs-Horizontal method for the detection of Salmonella spp. International Organization for Standardization (ISO), Geneva, Switzerland.

ISO. 2004. ISO 11290-1:2004. Microbiology of the food chain-Horizontal method for the detection and enumeration of Listeria monocytogenes and other Listeria spp. Part 1: Detection method. International Organization for Standardization (ISO), Geneva, Switzerland.

Jóźwik, A., E. Bagnicka, A. Śliwa-Jóźwik, N. Strzalkowska, K. Sloniewski, J. Krzyźewsky, and A. Kolątaj. 2004. Activity of selected aminopeptidases of whole milk in cows as related to feeding season (autumn/winter vs spring/summer). Anim. Sci. Pap. Rep. 22:667-672.

Kannan, G., T. H. Terrill, B. Kouakou, and S. Galipali. 2007. Blood metabolite changes and live weight loss following brown seaweed extract supplementation in goats subjected to stress. Small Rumin. Res. 73:228-234.

Karatzia, M., E. Christaki, E. Bonos, C. Karatzias, and P. Florou-Paneri. 2012. The influence of dietary Ascophyllum nodosum on haematologic parameters of dairy cows. Ital. J. Anim. Sci. 11:169-173.

Larsen, L. B., M. D. Rasmussen, M. Bjerring, and J. H. Nielsen. 2004 Proteases and protein degradation in milk from cows infected with Streptococcus uberis. Int. Dairy J. 14:899-907.

Li, N., R. Richoux, M. Boutinaud, P. Martin, and V. Gagnaire. 2014 Role of somatic cells on dairy processes and products: A review. Dairy Sci. Technol. 94:517-538.

Marchand, S., K. Heylen, W. Messens, K. Coudijzer, P. De Vos, K. Dewettinck, L. Herman, J. De Block, and M. Heyndrickx. 2009. Seasonal influence on heat-resistant proteolytic capacity of Pseudomonas lundensis and Pseudomonas fragi, predominant milk spoilers isolated from Belgian raw milk samples. Environ. Microbiol. 11:467-482.
Ministero Delle Politiche Agricole e Forestali. 1998. 21 dicembre 1998 Approvazione dei metodi di analisi per il controllo ufficiale degli alimenti per animali e soppressione di altri metodi inerenti al controllo del medesimo settore merceologico. G.U. n. 231 del 08/02/1999 suppl. 13

Moschini, M., M. Battaglia, G. M. Beone, G. Piva, and F. Masoer. 2010. Iodine and selenium carry over in milk and cheese in dairy cows: Effect of diet supplementation and milk yield. Animal 4:147155.

Mosulishvili, L. M., E. I. Kirkesali, A. I. Belokobylsky, A. I. Khizanishvili, M. V. Frontasyeva, S. S. Pavlov, and S. F. Gundorina. 2002. Experimental substantiation of the possibility of developing selenium- and iodine-containing pharmaceuticals based on blue-green algae Spirulina platensis. J. Pharm. Biomed. Anal. 30:87-97.

Norouzian, M. A. 2011. Iodine in raw and pasteurized milk of dairy cows fed different amounts of potassium iodide. Biol. Trace Elem. Res. 139:160-167.

Olivieri, A., and P. Vitti, ed. 2014. Monitoring of the nation wide program of iodine prophylaxis in Italy. Rapporti ISTISAN 14/6 Roma.Istituto Superiore di Sanità. Rome, Italy.

Phaneuf, D., I. Côté, P. Dumas, L. A. Ferron, and A. LeBlanc. 1999 Evaluation of the contamination of marine algae (seaweed) from the St. Laurence river and likely to be consumed by humans. Environ. Res. 80:S175-S182.

Quigley, L., O. O'Sullivan, C. Stanton, T. P. Beresford, R. P. Ross, G. F. Fitzgerald, and P. D. Cotter. 2013. The complex microbiota of raw milk. FEMS Microbiol. Rev. 37:664-698.

Raats, D., M. Offek, D. Minz, and M. Halpern. 2011. Molecular analysis of bacterial communities in raw cow milk and the impact of refrigeration on its structure and dynamics. Food Microbiol. $28: 465-471$

Reynolds, C. K., V. L. Cannon, and S. C. Loerch. 2006. Effects of forage source and supplementation with soybean and marine algal oil on milk fatty acid composition of ewes. Anim. Feed Sci. Technol. 131:333-357.

Saker, K. E., V. G. Allen, J. P. Fontenot, C. P. Bagley, R. L. Ivy, R. R. Evans, and D. B. Wester. 2001. Tasco-forage: II. Monocyte immune cell response and performance by beef steers grazing tall fescue treated with a seaweed extract. J. Anim. Sci. 79:1022-1031.

Schöne, F., M. Leiterer, P. Lebzien, D. Bemmann, M. Spolders, and G Flachowsky. 2009. Iodine concentration of milk in a dose-response study with dairy cows and implications for consumer iodine intake. J. Trace Elem. Med. Biol. 23:84-92.

Secchiari, P., M. Antongiovanni, M. Mele, A. Serra, A. Buccioni, G. Ferruzzi, F. Paletti, and F. Petacchi. 2003. Effect of kind of dietary fat on the quality of milk fat from Italian Friesian cows. Livest. Prod. Sci. 83:43-52.

Serio, A., C. Chaves-López, A. Paparella, and G. Suzzi. 2010. Evaluation of metabolic activities of enterococci isolated from Pecorino Abruzzese cheese. Int. Dairy J. 20:459-464.

Smalla, K., U. Wachtendorf, H. Heuer, W. Liu, and L. Forney. 1998. Analysis of BIOLOG GN substrate utilization patterns by microbial communities. Appl. Environ. Microbiol. 64:1220-1225.

Spolaore, P., C. Joannis-Cassan, E. Duran, and A. Isambert. 2006 Commercial applications of microalgae. J. Biosci. Bioeng. 101:8796.

Suchodolski, J. S., S. E. Dowd, V. Wilke, J. M. Steiner, and A. E. Jergens. 2012. 16S rRNA gene pyrosequencing reveals bacterial dysbiosis in the duodenum of dogs with idiopathic inflammatory bowel disease. PLoS ONE 7:e39333.

Turner, J. L., S. Dritz, J. J. Higgins, and J. E. Minton. 2002. Effects of Ascophyllum nodosum extract on growth performance and immune function of young pigs challenged with Salmonella typhimurium. J. Anim. Sci. 80:1947-1953.

van Ginneken, V. J. T., J. P. F. G. Helsper, W. de Visser, H. van Keulen, and W. A. Brandeburg. 2011. Polyunsaturated fatty acids in various macroalgal species from north Atlantic and tropical seas. Lipids Health Dis. 10:104.

van Knegsel, A. T., M. Hostens, G. De Vries Reilingh, A. Lammers, B. Kemp, G. Opsomer, and H. K. Parmentier. 2012. Natural antibod- 
ies related to metabolic and mammary health in dairy cows. Prev. Vet. Med. 103:287-297.

Wang, X. A. 1995. Study of the content, distribution and chemical species of Laminaria japonica (in Chinese). MS Thesis. China Institute of Oceanology, Academia Sinica, Qingda, China.

Watutantrige Fernando, S., S. Barollo, D. Nacamulli, D. Pozza, M. Giachetti, F. Frigato, M. Redaelli, G. Zagoto, M. E. Girelli, F. Mantero, and C. Mian. 2013. Iodine status in schoolchildren living in northeast Italy: The importance of iodized-salt use and milk consumption. Eur. J. Clin. Nutr. 67:366-370.

WHO/UNICEF/ICCIDD (World Health Organization/United Nations Children's Fund/International Council for Control of Iodine Deficiency Disorders). 2007. Assessment of iodine deficiency dis- orders and monitoring their elimination. A guide for programme managers. WHO Press, Geneva, Switzerland.

Yanagibashi, T., A. Hosono, A. Oyama, M. Tsuda, A. Suzuki, S. Hachimura, Y. Takahashi, Y. Momose, K. Itoh, K. Hirayama, K. Takahashi, and S. Kaminogawa. 2013. IgA production in the large intestine is modulated by a different mechanism than in the smal intestine: Bacteroides acidifaciens promotes $\operatorname{Ig} \mathrm{A}$ production in the large intestine by inducing germinal center formation and increasing the number of IgA + B cells. Immunobiology 218:645-651.

Zdanowicz, M., J. A. Shelford, C. B. Tucke, D. M. Weary, and M. A. G. von Keyserlingk. 2004. Bacterial populations on teat ends of dairy cows housed in free stalls and bedded with either sand or sawdust. J. Dairy Sci. 87:1694-1701. 